William Bülow (Opinion Paper):

\title{
Pluralism about the Value of Privacy
}

\begin{abstract}
:
This paper responds to two counterexamples to the view that privacy is valuable because of its connection to personal autonomy. It is argued that these counterexamples fail to establish that personal autonomy is not relevant for the value of privacy, but only the cautious claim that respect for personal autonomy alone is not the only reason for which privacy ought to be respected. Based on the response to the counterexamples a distinction between value-monistic and value-pluralistic accounts about the value of privacy is introduced and it is argued that there are reasons for accepting a value-pluralistic approach to privacy.
\end{abstract}

\section{Agenda}

Introduction

Counterexamples to autonomy-based accounts of the value of privacy

Value-pluralism about privacy

Final remarks

\section{Author:}

Mr. William Bülow (M.A)

- Division of Philosophy, KTH Royal Institute of Technology, Teknikringen 78 B, 10044 Stockholm, Sweden

- 谓 + $46733336317, \square$ william.bulow@abe.kth.se 


\section{Introduction}

The current debate on the concept of privacy certainly indicates the complexity of this concept. While all classical theories of privacy have attractive characteristics they all face difficult problems. One might say that on each account something is missing and it does not provide the whole story. The same observation, it seems, holds for discussions on the value of privacy. Why, exactly, is privacy held to be valuable and why ought there to be a right to privacy? In order to account for this issue, different suggestions have been given, such as the respect for human dignity ${ }^{1}$, its connection to personal autonomy ${ }^{2}$ or that privacy concerns is as an expression for the need of safety and security. ${ }^{3}$

In this paper focus will be on one proposal, namely that privacy is valuable because of its connection to personal autonomy. More specifically, this paper will focus on two counterexamples that aim at refuting the claim that privacy is important because of this supposed connection. While these arguments are presented against the view that privacy derives its value from the value of personal autonomy, it is not obvious that they are successful in doing this. Instead I will argue that if these counterexamples establish anything, this is only the more cautious claim that privacy is not valuable because of its connection to personal autonomy alone (Section 1). Based on this insight I will introduce a distinction between value-monistic accounts about the value of privacy and value-pluralistic accounts. According to value-monistic accounts privacy derives its value from one source and one source only. In contrast value-pluralism holds that privacy derives its value from a plural of sources and not from one alone. In this section I suggest that we do have reasons for embracing a value-pluralistic account (section 2). Finally, I will make some concluding remarks about the argument presented here (Section 3).

\section{Counterexamples to autonomy-based accounts of the value of privacy}

In the philosophical literature on privacy several authors have suggested that the value of privacy derives its value from personal autonomy. ${ }^{4}$ That is, the protection of privacy is a safeguard for the protection of undesirable access of others and is necessary for individuals in order to be able to control aspects of themselves in a self-determent way. This view is at least prima facie plausible. As he points out in his famous paper "Why privacy is Important", James Rachels suggests that privacy is important because of its social function, enabling us to control how we present ourselves to others which is crucial in order to uphold and create different sorts of relationships. ${ }^{5}$ Also, as Rössler emphasizes that the loss in control over personal information may come to limit individuals' autonomy. She writes:

"If it can in principle no longer be taken for granted that one has control over one's informational selfdetermination or that one is not (constantly) being observed, and if, as a result, one must (constantly) present oneself as though one were being observed, the result is a loss of autonomy in terms of the authenticity of one's behaviour, which is turned into behaviour as if, that is alienated behaviour. ${ }^{\prime 6}$

Focusing on privacy and its connection to autonomy, authors have argued that there are counterexamples in which privacy is violated while there is no violation to peoples' personal autonomy. One proposed argument against autonomy-based conceptions of privacy is that when we encounter instances where a person is incapable of autonomous decisions, this person still has privacy claims. A person in a coma has privacy interests but is incapable of making autonomous decisions, which is held to imply that autonomy is not

\footnotetext{
${ }^{1}$ von Silva-Tarouca Larsen, Beatrice: Setting the Watch: Privacy and the Ethics of CCTV Surveillance

${ }^{2}$ Rössler, Beate: The Value of Privacy

${ }^{3}$ Moor, James: Towards a theory of privacy for the information age

${ }^{4}$ Johnson, Debora: Computer ethics; Palm, Elin: Securing privacy at work: the importance of contextualized consent; Rössler, Beate: The Value of Privacy

${ }^{5}$ Rachels, James: Why privacy is Important

${ }^{6}$ Rössler, Beate: The Value of Privacy pp. 128-9.
} 
always an issue in connection with privacy claims. Von Silva-Tarouca Larsen suggests that this provides a reason for seeing respect for human dignity, rather than the respect for personal autonomy as the source of value for privacy. ${ }^{7}$

A different argument, put forth by James Moor, points out that it is possible to imagine a person, $A$, who secretly searches a person B's financial records, medical records and criminal records etc. Also, A knows about B's late mortgage payments, propensity to hemorrhoids, and that B once had a driving while intoxicated charge that B has long forgotten about. A is has also installed cameras in B's home which records Bs' every moment. However, B knows nothing about this. A really enjoys watching B's life and to him it is like a soap opera. According to Moor there is something disturbing about A's behavior. But $A$ is not sharing any of the information, nor is he hurting $B$ in any way. Moreover, Moor concludes, this does not violate Bs' autonomy. In contrast Moor suggests that privacy is valuable because it is an expression of a need for security and safety. ${ }^{8}$

While these arguments are presented as arguments against the view that privacy derives its value from the value of personal autonomy, it is not obvious that they are successful in doing this. In order to see this we must analyze what is actually at stake and what the premises of these arguments are. I suggest that both arguments share a similar structure which can be summarized as follows:

1. If an autonomy-based conception of the value of privacy is correct, every privacy violation can be explained in terms of violations to personal autonomy.

2. There are instances in which privacy is violated but personal autonomy is not.

3. Hence, autonomy-based accounts of the value of privacy are incorrect.

In response to this sort of arguments one might deny premise 2, a strategy that is defended elsewhere. ${ }^{9}$ But despite whether any of these arguments are successful or whether any of the proposed counterexamples are convincing, there is yet another problem with the arguments posted by von Silva-Tarouca Larsen and Moor. What both Moor and Silva-Tarouca Larsen try to prove is that while privacy is valuable, this is not because of its connection to personal autonomy. But in order to do so, they must first assert that either privacy is valuable because of its connection to personal autonomy, or personal autonomy is irrelevant for the value of privacy. This, however, seems like a very hasty and queer assumption. Why, exactly, should we assume that if privacy is valuable, it gains it value from one source and one source only? There are no good reasons for accepting this assumption without argument. In fact, I believe that by making this assumption explicit, it becomes obvious what is strange about the argument and why the conclusions drawn are too hasty. Instead, if the arguments proposed by Moor and von Silva-Tarouca Larsen shows anything at all, it is that respect for personal autonomy alone is not the only reason for which privacy ought to be respected. It is not enough to establish the claim that privacy gain no value whatsoever from its connection to personal autonomy.

\section{Value-pluralism about privacy}

So far, it has been argued that neither Moor's nor Silva-Tarouca Larsen's arguments are successful in refuting personal autonomy as a value-giving feature to privacy. Based on this insight it is beneficial for the discussion to introduce a basic distinction between theories about the value of privacy. First there are valuemonistic accounts about the value of privacy, according to which privacy derives its value from one source and one source only. In contrast there are value-pluralistic accounts about the value of privacy, according to which privacy derives its value from a plural of sources and not from one alone. Taking this distinction into account it is clear that Moor and Silva-Tarouca Larsen are successful in refuting value-monistic versions of autonomy-based accounts about the value of privacy. But they are not successful in refuting valuepluralistic versions in which privacy derives its value partly from personal autonomy.

\footnotetext{
${ }^{7}$ von Silva-Tarouca Larsen, Beatrice: Setting the Watch: Privacy and the Ethics of CCTV Surveillance

${ }^{8}$ Moor, James: Towards a theory of privacy for the information age

${ }^{9}$ Bülow, William,. Wester, Misse: The Right to Privacy and the Protection of personal data in a Digital Era and the Age of Information
} 
What is important in this context is that not only do Moor's and Silva-Tarouca Larsen's fail to refute the claim that personal autonomy is a value-giving feature to privacy, but also their own proposals are not incompatible with this claim. That respect for privacy is important because of its connection to personal autonomy does not exclude neither Moor suggestion that privacy is important because it is a expression for safety nor von Silva-Tarouca Larsen that respect for privacy derives its value from the notion of human dignity. None of them is in a necessary conflict with the idea that respect for privacy often provide us with a reason for respecting privacy. Hence, one can (and perhaps should) embrace a value-pluralistic view on privacy including all of these proposals. In fact, is not hard to imagine a case where at least two or more of these reasons are involved: that is, they are all violated as a result of a privacy violation. The case of aggregating digital data, for instance, may both decrease safety as well as violate personal autonomy if it is being misused. Furthermore, adopting a value-pluralistic account fits well with how we reason about privacy issues and how we express concerns about possible privacy issues and how different reasons are often given in favour of privacy protection. Taking Moor's proposal that privacy concerns are an expression for the need of safety we don't want every information about ourselves available to everyone, since it makes us vulnerable. Reduced privacy enhances the risk for what informational-based harms such as stalking or perhaps identity theft. If we consider personal autonomy surveillance and the fact that we may be under surveillance affects and shapes our behavior and hence decrease our personal autonomy. Finally, if we consider the privacy concerns of a coma patient who is unlikely to recover we may say that it is against human dignity not to respect his privacy. In each case, the reasons given in favour of privacy protection or in the name of privacy make sense and cannot necessarily be generalized to other privacy issues. That privacy is important for several reasons, and hence derives its value and importance from plural sources does not come as a surprise. Despite this, further developing pluralism about the value of privacy could provide a good analytical framework for evaluating ethical problems involving privacy. For these reasons it is concluded that value-pluralism about the value of privacy is plausible and should be held to be an interesting approach towards solving the axiological problems of privacy.

\section{Final remarks}

I have argued that there are reasons for adopting what I have called a value-pluralistic account of privacy. So far, however, I have not provided with a clear picture of its content, but merely given an account for its structure. Also, I have assumed without argument that the value of privacy is a derived value. Perhaps this is false and that privacy is a fundamental value in its own right. However, I haven't seen any arguments for this view and since the account I have proposed is both plausible and shows how we can solve certain problems within the discussion about privacy and its value I leave it to others to prove that this is actually the case.

\section{References}

Bülow, W., Wester, M. (Forthcoming). The Right to Privacy and the Protection of personal data in a Digital Era and the Age of Information, i Akrivopoulou, Ch. M., Garipidis, N. (red.) Human Rights and Risks in the Digital Era: Globalization and the Effects of Information Technologies. Pennsylvania: IGI Global.

Johnson, D.G. (2001). Computer ethics. (3. ed.) Upper Saddle River, N.J.: Prentice Hall.

Moor J. (2004). Towards a theory of privacy for the information age in Bynum, T. W., Rogerson, S. (ed), Computer ethics and professional responsibility, (pp. 249-262). Malden, Mass. : Blackwell Publishing:

Palm, E. (2009). "Securing privacy at work: the importance of contextualized consent", Ethics and Information Technology 11: 233-241

Rachels, J. (1975), "Why Privacy is Important" Philosophy and Public Affairs

Rössler, B. (2005). The Value of Privacy, Cambridge, Polity Press.

Von Silva-Tarouca Larsen, B. (2011). Setting the Watch: Privacy and the Ethics of CCTV Surveillance. Oxford: Hart. 